\title{
U-GOV Portal: The University Portal as the access point to the services for the University community
}

\author{
Rosita Bacchelli, Cyril Reinhard, Federico Gallerani \\ Keywords \\ Web, Drupal, opensource, Portal, Websites.
}

\section{U-GOV PORTAL: THE UNIVERSITY PORTAL AS THE ACCESS POINT TO THE SERVICES FOR THE UNIVERSITY COMMUNITY}

With their rapid development, digital technologies have transformed systems within Higher Education, redefining its reference standards and models. Today a modern university interacts with its users through digital media, makes available online all the key information for presenting the institution's profile and the offer and provides access to the online services profiled based on the characteristics of each user in multichannel mode. For this reason the new technologies and service innovation have been the main focus of interest and investments of universities.

The new university portal development models required considerable effort on the institution's part to define their digital strategy and the consequent coordination of the computer components that process data and services and of the different organisational structures that manage them. The first aspect to be dealt with is the integration of information and resources. The University Portal provides the tools for orchestrating and managing complexity, integrating and spreading information on numerous channels.

Universities are characterised by great organisational complexity, which includes departments, service centres and other autonomous organisational units. The Portal has to offer an ecosystem which, through extreme flexibility, makes it possible to make the most of the well-organised structures, the independence and the individual services, at the same time leading back and unifying the supply of different contents and services to a sole digital identity design.

The quality of the services provided online has a direct impact on the quality of the service, as well as on the attractiveness and prestige of the university. The main national and international rankings that evaluate and classify universities take into consideration precisely the quality and completeness of the digital content and services and the ease of access and browsing by users as important drivers when coming up with the final rating.

Cineca, within the context of the U-GOV Solution - the integrated application system for the governance of universities and research agencies, has developed a University Portal solution on Drupal open source platform.

U-GOV Portal is an integrated information and services system dedicated to the entire university community through which to work, communicate and collaborate online. It involves the teaching body, students, researchers and the administration, but also businesses, prospective students and schools, government ministries, local public administration and the press, as well as other subjects with whom the university wishes to establish and maintain relationships.

U-GOV Portal created on Drupal offers universities the solution for assembling a web ecosystem based on the following components:

- Public Institutional Portal

- Federated sites: departments, centres, educator sites, collaborative areas, etc.

- MyPortal: profiled reserved area, access point unified to all online services that the user can access based on his/her profile and authorisations

Thanks to the extreme flexibility of the Drupal platform, which boasts one of the vastest open source communities in the world with over 850,000 users in 228 countries and over 21,000 developers who maintain and make available over 18,500 modules, the U-GOV Portal solution is able to offer universities a dynamic and complete solution always capable of addressing the basic requirements of a modern portal: 
- User Experience

- Mobile first: Mobile, Tablet and Desktop experience

- Integration with management systems: data display in the public area and online services in the profiled area

- Regulatory compliance

- Modularity and personalisation

- Advanced authoring and distributed editing with workflow

- Open source and reuse: contained maintenance and evolutionary development costs

With the goal of offering universities maximum quality in terms of best practice, performance, scalability and functional coverage, CINECA has chosen to work with Acquia, the company founded by Drupal project lead \& founder Dries Buytaert.

Acquia supports CINECA and the U-GOV Portal solution developed on Drupal providing technical support, knowledge-base, tools and professional consulting services.

Many leading Italian universities have chosen to create their University Portal with U-GOV Portal developed on Drupal: Sapienza University of Rome, University of Siena, University of Parma, University of Brescia, Unitelma Sapienza - Telematic University and many others.

During the session the technological and methodological aspects of the U-GOV Portal developed on Drupal will be presented and discussed through two especially successful cases: the portal of La Sapienza University of Rome - the largest university in Europe - and the portal of the University of Siena, developed according to the Mobile First and Responsive Web Design approaches to guarantee full use through mobile devices as well.

\section{AUTHORS' BIOGRAPHIES}

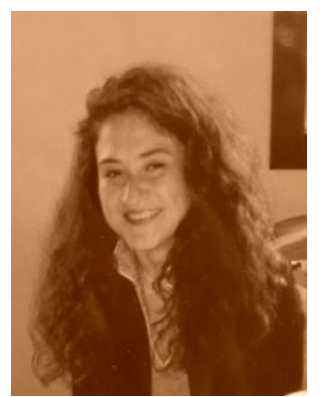

\section{Rosita Bacchelli}

She studied Information technology at Università degli Studi di Modena e Reggio Emilia. Head of Cineca's Web Portals BU, she coordinates a team of 15 people highly motivated with strong skills on web technologies, mobile, open source, Drupal, user experience and Higher Education sector. With the team she has been developing websites for Public Sector and Universities since 1996, on Drupal since 2008 and since 2011 the solution is part of the U-GOV Solution the integrated application system for the governance of universities and research agencies developed by Cineca.

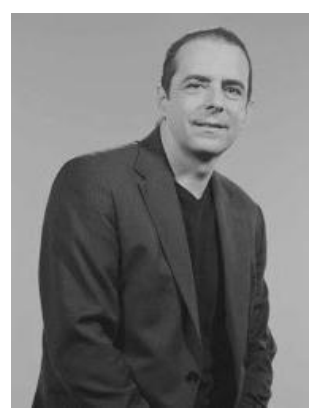

\section{Cyril Reinhard}

After several years with software publishers (ILOG Acquired by IBM, Hyperwave, ENIGMA Inc) and more than 8 years entrepreneurial experience, he joined Adobe Systems France in 2006, with whom he had entered into a strategic partnership with his company Sowedoo Software. Firmly believing that Open Source and/or SaaS are the future of the software industry, he joined Acquia in March 2012 as Regional Director. Cyril participated in roundtables around the Open Data, cross-channel User Experience, social engagement. He is also a member of the jury of the DataConnexion challenge around French Open Data. $\mathrm{He}$ is also a teacher and he leads the MTI (Web, Mobile \& Social Technologies) specialization of EPITA (IT Engineer School).

He holds a degree in Computer Engineering from EPITA and a Masters in Computer Mathematics Applied to Social Sciences, Sorbonne University Paris 1 / ENST. 


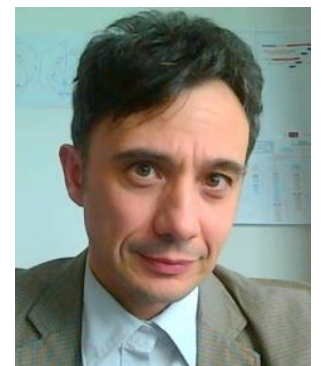

\section{Federico Gallerani}

Gallerani, as CINECA's technologist, is product responsible for the U-GOV Solution (Integrated System for University GOVernance) and coordinates the Product Manager team.

He has been working in the field of Information Systems for Higher Education since 2003 participating in several projects regarding system integration and interoperability. 